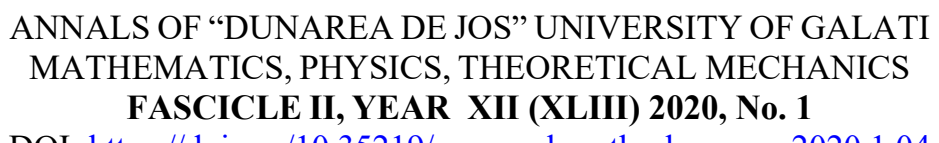

DOI: https://doi.org/10.35219/ann-ugal-math-phys-mec.2020.1.04

\title{
Vibrational investigation of the 3,4-methylenedioxypyrovalerone designer drug
}

\author{
Adelina Ion ${ }^{1}$, Steluta Gosav ${ }^{1}$, Mirela Praisler ${ }^{1, *}$ \\ 1 "Dunarea de Jos" University of Galati, Faculty of Sciences and Environment, INPOLDE research center, \\ 800008 Galati, Romania \\ *Corresponding author: Mirela.Praisler@ugal.ro
}

\begin{abstract}
One of the most important synthetic cathinones, which is a popular family of designer drugs, is 3,4methylenedioxypyrovalerone (MDPV). This $\beta$-keto phenylalkylamine, which represents a derivative of the natural alkaloid cathinone found in the Catha edulis plant, was detected for the first time in 2007 in Japan and was classified by the Drug Enforcement Agency of the United States (DEA) as a Schedule I drug [1-3]. This paper presents a broad vibrational characterization of MDPV, by using IR spectroscopy combined with Density Functional Theory (DFT) calculations. The basis of the quantum mechanical calculations performed, in the ground state, was the B3LYP hybrid functional with $6-311 \mathrm{G}(\mathrm{d}, \mathrm{p})$. The evaluation of the vibrational frequencies was performed by analyzing the energy secondary derivatives, which were determined on the basis of harmonization. The process led to detailed vibrational allocations of the absorption bands, which were performed on the basis of the potential energy distribution (PED). The proposed method has led to a very good agreement between the computed and the experimental frequencies.
\end{abstract}

Keywords: synthetic cathinone, MDPV, DFT, vibrational analysis.

\section{INTRODUCTION}

A class of frequently traded synthetic drugs consists of synthetic cathinones. An important member of this class is 3,4-methylenedioxypyrovalerone (MDPV), a $\beta$-keto-phenylalkylamine that is a derivative of the natural alkaloid cathinone found in the Catha edulis plant (see Figure 1) [1-3].

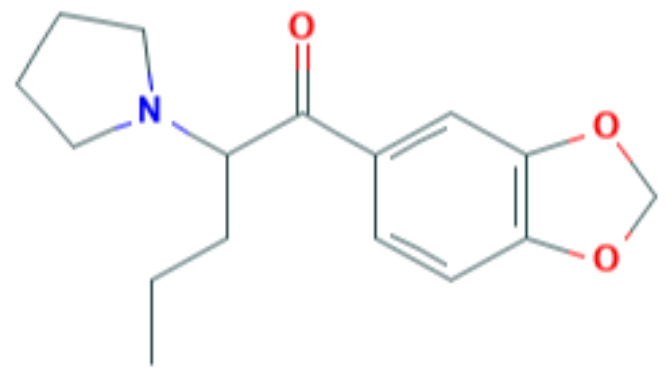

Fig. 1. Molecular structure of 3,4-methylenedioxypyrovalerone [4].

3,4-methylenedioxypyrovalerone (MDPV) is a psychoactive substance of the phenethylamines class, which, from a structural point of view, is closely related to 3,4methylenedioxymethamphetamine (MDMA), methamphetamine, cathinone, and other phenethylamines. MDPV is sold through illicit channels as "bath salts" (Ivory Wave, plant fertilizer, 
Vanilla Sky, or Energy-1) and has a stimulating effect on the central nervous system (CNS). Various studies have reported its hallucinogenic effects [2,5-6].

The aim of this study was to characterize MDPV by IR spectroscopy in correlation with the functional density theory (DFT). Quantum mechanical calculations were performed in the solid state using the functional B3LYP hybrid with 6-311G $(\mathrm{d}, \mathrm{p})$ as the established basis. The vibrational allocation of the absorption bands was made on the basis of the potential energy distribution (PED). This distribution is important because it allows the characterization of the relative contributions starting with each internal coordinate to the total potential energy associated with the normal coordinate of the studied molecule.

\section{EXPERIMENTAL}

The optimization of the complete geometry in the gas phase for the investigated molecule was performed by using the Gaussian 09 software [7]. Following the optimization, the geometric parameters were obtained, i.e. the length between the connections, the angle between the connections and the torsion angle. The geometric parameters and IR frequencies were determined based on the DFT theory, by using the functional hybrid B3LYP and 6-311G $(d, p)$ as the basic set. Thus, the optimized geometry is situated at a generalized minimum on the surface of the potential energy.

The analysis in terms of contributions of the theoretical vibrational spectrum of the compound 3,4-methylenedioxypyrovalerone was performed by using the VEDA 4 software [8].

\section{RESULTS AND DISCUSSION}

The first result obtained, after performing all the steps described above, is the determination of the optimized molecular structure of 3,4-methylenedioxypyrovalerone (MDPV), which is represented in Figure 2.

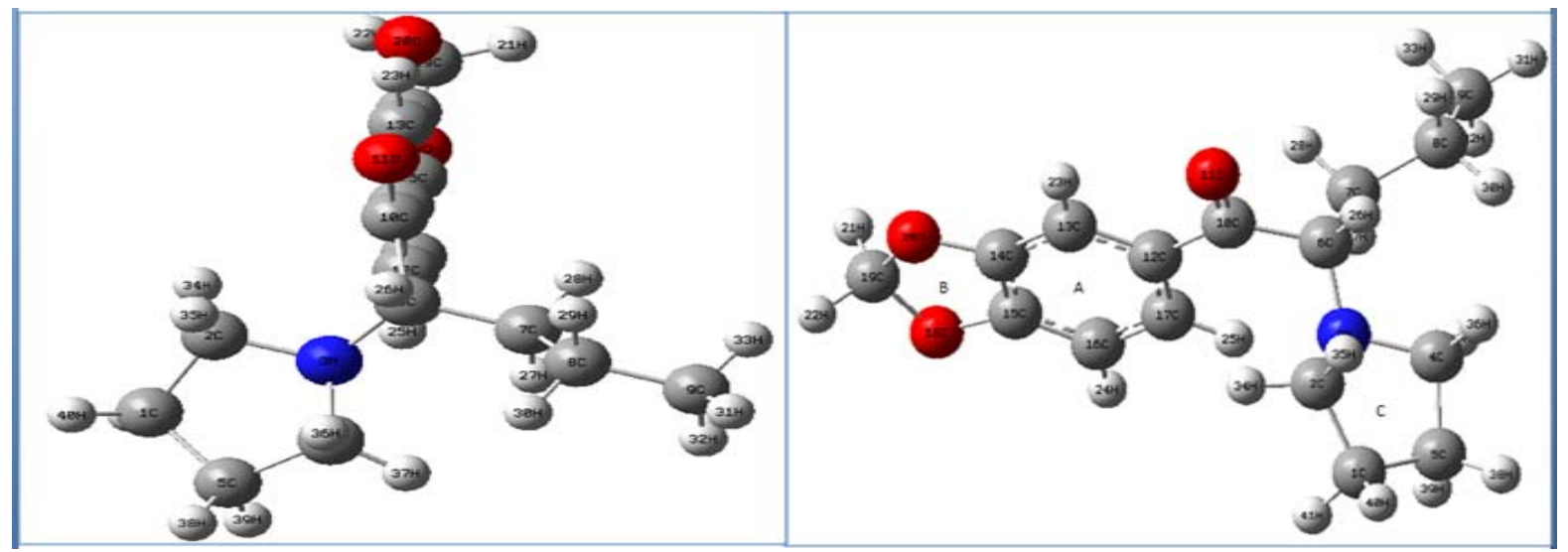

Fig. 2. Optimized molecular structure of 3,4-methylenedioxypyrovalerone (MDPV).

Figure 3 presents the calculated IR spectra and the experimental spectra of MDPV in the spectral region $3500-400 \mathrm{~cm}^{-1}$. It indicates the similarity between the theoretical and experimental spectra. Some minor differences in the intensity or position of the absorption bands are due to the fact that the experimental spectrum corresponds to the solid phase of 3,4-methylenedioxypyrovalerone, and the theoretical spectrum corresponds to its gaseous phase.

The experimental and theoretical IR spectra of 3,4-methylenedioxypyrovalerone (MDPV) are presented in Table 1. 


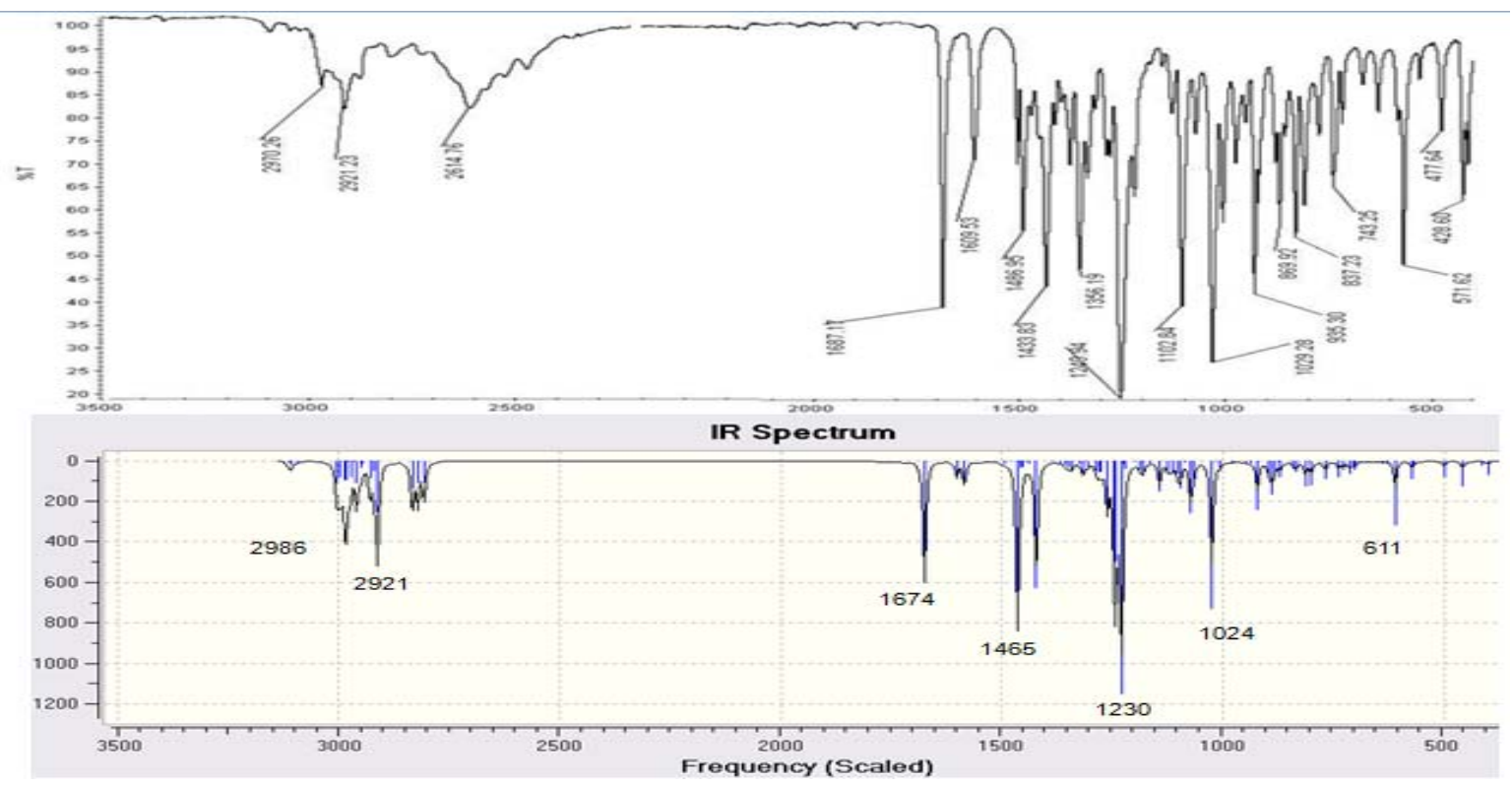

Fig. 3. Experimental [9] and theoretical IR spectra of 3,4-methylenedioxypyrovalerone (MDPV) in the spectral region $3500-400 \mathrm{~cm}^{-1}$.

Table 1. The experimental and theoretical IR spectra of 3,4-methylenedioxypyrovalerone (MDPV)

\begin{tabular}{|c|c|c|c|c|c|}
\hline No. & $\begin{array}{l}I R_{\text {teoretic }} \\
\text { intensity }\end{array}$ & $\begin{array}{l}\bar{v}_{\text {theor. }} \\
\left(\mathrm{cm}^{-1}\right)\end{array}$ & $\begin{array}{l}\bar{v}_{\text {scaled }} \\
\left(\mathrm{cm}^{-1}\right)\end{array}$ & $\begin{array}{l}\bar{v}_{\text {exp }} \\
\left(\mathrm{cm}^{-1}\right)\end{array}$ & $\begin{array}{c}\text { Assignment of vibrational modes in term of } \\
\text { potential energy distribution } \\
P E D(\%)\end{array}$ \\
\hline 1. & 11,27 & 3214 & 3105 & 3090 & $v^{s}(C H)_{a r, \text { ring }}[85](C 16, C 17)$ \\
\hline 2. & 55,21 & 3088 & 2983 & 2970 & $v^{a s}(\mathrm{CH})_{a l}[93]\left(\mathrm{C} \mathrm{H}_{2}\right)$ \\
\hline 3. & 142,13 & 3012 & 2910 & 2921 & $v^{s}(\mathrm{CH})_{\text {ring } B}[79]\left(\mathrm{Cl}_{2}\right)$ \\
\hline 4. & 174,27 & 1732 & 1673 & 1687 & $v(C=O)[89]$ \\
\hline 5. & 24,32 & 1657 & 1601 & 1610 & $v(C C)_{a r, \text { ring } A}[60]$ \\
\hline 6. & 232,86 & 1515 & 1464 & 1487 & $v(C C)_{a r, \text { ring } A}[23]+\beta^{s c}(C C H)_{\text {ringA }}[21]$ \\
\hline 7. & 172,49 & 1471 & 1420 & 1434 & $\beta^{s c}(C C H)_{\text {ring } A}[25]+v(C C C)_{\text {ring } A}[16]$ \\
\hline 8. & 11,12 & 1389 & 1342 & 1356 & $v(C C)_{\text {ring } A}[60]$ \\
\hline 9. & 134,91 & 1288 & 1244 & 1250 & $\beta^{s c}(C C H)_{\text {ring A }}[37]+v(C C)_{\text {ring } A}[17]$ \\
\hline 10. & 28,78 & 1135 & 1096 & 1103 & $\beta(C C C)_{\text {ring } A}[16]+\beta(C C H)_{\text {ring } A}[18]$ \\
\hline 11 & 144,89 & 1061 & 1025 & 1029 & $v^{s}(O C)_{\text {ring } B}[43]+\beta(C O C)_{\text {ring } B}[24]$ \\
\hline 12. & 42,83 & 954 & 922 & 935 & $v^{a s}(O C)_{r i n g B}[36]+\beta(C O C)_{r i n g ~}[25]$ \\
\hline 13. & 28,50 & 921 & 890 & 870 & $v(N C)_{\text {ring } C}[15]$ \\
\hline 14. & 6,04 & 869 & 839 & 837 & $\tau(H C N C)_{\text {ring } C}[26]$ \\
\hline 15. & 13,35 & 795 & 768 & 743 & $\tau(\mathrm{CCCH})[15](\mathrm{C} 7 \mathrm{C} 8 \mathrm{C} 9 \mathrm{H} 33)$ \\
\hline 16. & 37,44 & 632 & 610 & 571 & $\beta(C N C)[53](C 6 N 3 C 2)$ \\
\hline 17. & 7,30 & 516 & 498 & 478 & $\beta(C N C)[26](C 4 N 3 C 6)$ \\
\hline 18. & 5,08 & 414 & 400 & 429 & $\beta(C N C)[21](C 6 N 3 C 2)$ \\
\hline
\end{tabular}

Abbreviations: $v$ - stretching, $\beta$ - in-plane deformation, $\beta^{\text {out }}$ - out-of-plane deformation, $\tau$ - torsion, ar aromatic, al - aliphatic, $s$ - symmetric; as - asymmetric; PED $<15 \%$ are not shown. 
Analyzing Table 1, we can notice that the stretching vibrations, $v(\mathrm{CH})$, are found in the spectral region 3105-2910 $\mathrm{cm}^{-1}$ at the level of B3LYP / 6-311G (d, p), with relatively good PED percentages $(79-93 \%)$. The aliphatic stretching vibrations, $v(\mathrm{CH})_{a l}$, generate absorption bands at $2983 \mathrm{~cm}^{-1}$ in the theoretical IR spectrum and at $2970 \mathrm{~cm}^{-1}$ in the experimental FTIR spectrum. The symmetrical stretching vibration, which belongs to ring $\mathrm{B}$, is found at $2910 \mathrm{~cm}^{-1}$ in the simulated spectrum and at $2921 \mathrm{~cm}^{-1}$ in the experimental one.

The first band associated with an almost normal pure mode $v(C C)_{a r}$ (PED allocation being $60 \%$ ) for ring $\mathrm{A}$, is identified at $1601 \mathrm{~cm}^{-1}$ in the scaled theoretical spectrum and at $1610 \mathrm{~cm}^{-1}$ in the experimental theoretical spectrum.

The next bands are assigned to the normal mixed modes obtained by the combination of vibrations $v(C C)_{a r}$ and $\beta^{s c}(C C H)_{a r}$. In the experimental FTIR spectrum, these bands show at 1487 $\mathrm{cm}^{-1}$ and $1434 \mathrm{~cm}^{-1}$, respectively.

Torsional vibrations, $\tau(H C N C)$ and $\tau(C C C H)$, are found in the spectral region $839-768 \mathrm{~cm}^{-}$

${ }^{1}$ at the B3LYP / 6-311G (d, p) level, while the plane deformation vibrations, $\beta(C N C)$, are identified in the spectral range $571-429 \mathrm{~cm}^{-1}$, in the experimental FTIR spectrum.

\section{CONCLUSIONS}

The PED allocations of the vibrational modes indicate that the spectral range $3090-2921 \mathrm{~cm}^{-1}$ contains only normal vibrational modes, while in the finger print region most normal modes are mixed. The results indicate that a good agreement was obtained between the calculated vibrational modes and the experimental ones at the level of the DFT / (B3LYP) / 6-311G theory (d, p).

\section{References}

1. Coppola M., Mondola R., 3,4-Methylenedioxypyrovalerone (MDPV): chemistry, pharmacology and toxicology of a new designer drug of abuse marketed online, Toxicology Letters 12(5) (2012) 208.

2. Desharnais B., Dazé1 Y., Huppertz L.M., Mireault P., Skinner C.D., A case of fatal idiosyncratic reaction to the designer drug 3,4-methylenedioxypyrovalerone (MDPV) and review of the literature, Forensic Sci. Med. Pathol., 13(3) (2017) 350-354.

3. United States Department of Justice: Schedules of controlled substances: temporary placement of three synthetic cannabinoids into Schedule I. Final order. Fed Regist 78 (2013) 2873528739.

4. ***https://pubchem.ncbi.nlm.nih.gov/compound/Methylenedioxypyrovalerone

5. Boshuisen K., Arends J.E., Rutgers D.R., Frijns C.J., A young man with hemiplegia after inhaling the bath salt "Ivory wave", Neurology; 78 (19) (2012) 1533-1534.

6. ***https://www.deadiversion.usdoj.gov/drug chem info/mdpv.pdf (December 2019)

7. Gaussian 09 software package, Revision D.01, Frisch M. J.; Trucks G. W.; Schlegel H. B.; Scuseria G. E.; Robb M. A.; Cheeseman J. R.; et. All, Fox D. J. Gaussian, Inc., Wallingford CT, 2009.

8. Jamroz M.H., Vibrational Energy Distribution Analysis: VEDA 4 program, Warsaw, Poland, 2004.

9. ***https://www.dea.gov/sites/default/files/pr/microgram-journals/2010/mj7-1_12-15.pdf 